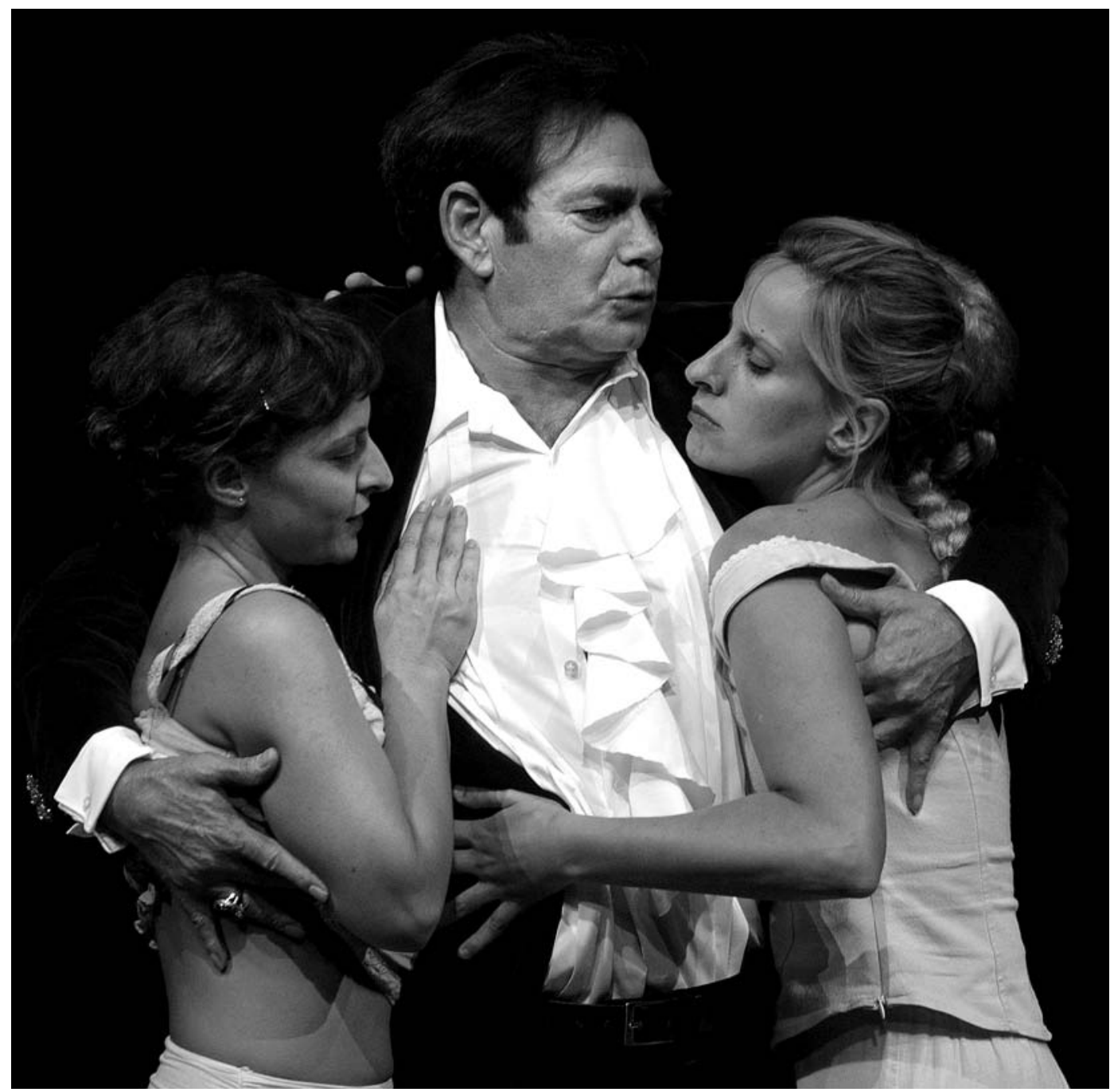

\title{
D. Juan de Molière com o seu criado Esganarelo em Almada
}

\section{Christine Zurbach}

Titulo: D. Juan (1665). Autor:Molière. Tradução: António Coimbra Martins. Encenação: Joaquim Benite. Cenografia: Manuel Graça Dias e Egas José Vieira. Luz: José Carlos Nascimento. Figurinos: Sónia Benite. Colaboração musical: Fernando Fontes. Intérpretes: Alberto Quaresma, André Gomes, Cecilia Laranjeira, Celestino Silva, Margarida Gonçalves, Marques D'Arede, Miguel Damião, Miguel Martins, Pedro Saavedra, Teresa Gafeira e André Albuquerque, Carlos Ramos e Filipe Neves. Concepção da estátua: Ildeberto Gama; Quadro (s/titulo, 1938): Luis Bernardo Leite de Ataíde. Produção: Companhia de Teatro de Almada. Local e data de estreia: Teatro Municipal de Almada, 28 de Setembro de 2006.

Esta recente (e também 100) produção da Companhia de Teatro de Almada tem um significado muito especial: é a primeira criação teatral da companhia no novo Teatro Municipal de Almada, um dos maiores e mais modernos palcos portugueses. Os arquitectos Graça Dias e José Egas Vieira, também cenógrafos do espectáculo, conceberam um verdadeiro equipamento cultural aberto, virado para a cidade e para os criadores de teatro.

A proposta de encenação de Joaquim Benite para a mais famosa comédia de Molière encontra a sua maior legibilidade em dois aspectos complementares no trabalho de criação teatral que nem sempre ganham idêntico relevo e eficácia na produção do espectáculo de teatro nos nossos dias.

0 primeiro traço que caracteriza este $D$. Juan, o último à data em Portugal na longa série das suas re-visitações teatrais ${ }^{1}$, é a sua inscrição numa estratégia consistente de repertório de uma companhia experiente nessa matéria. Mas tal dado reflecte, também, o percurso de um encenador cujo trabalho artístico já confirmou por diversas vezes um interesse evidente por um "teatro de texto", sendo que no caso presente - e será este o segundo traço relevante para esta análise -, a escolha recaiu num autor e numa obra que podemos considerar como emblemáticos feitas duas outras

encenaçōes sobre este texto de Molière: $D$. Juan ou o festim de pedra, pela Academia

Contemporânea do Espectáculo / Teatro do Bolhão, com encenação de Kuniaki Ida (/1 de Abril de 2005) e D. João, pelo Teatro Nacional S. João, encenado por Ricardo Pais (16 de Fevereiro de 2006). 


\section{Juan, \\ de Molière, \\ enc. Joaquim Benite, \\ Companhia de Teatro \\ de Almada, 2006 \\ (Marques D'Arede), \\ fot. José Frade.}

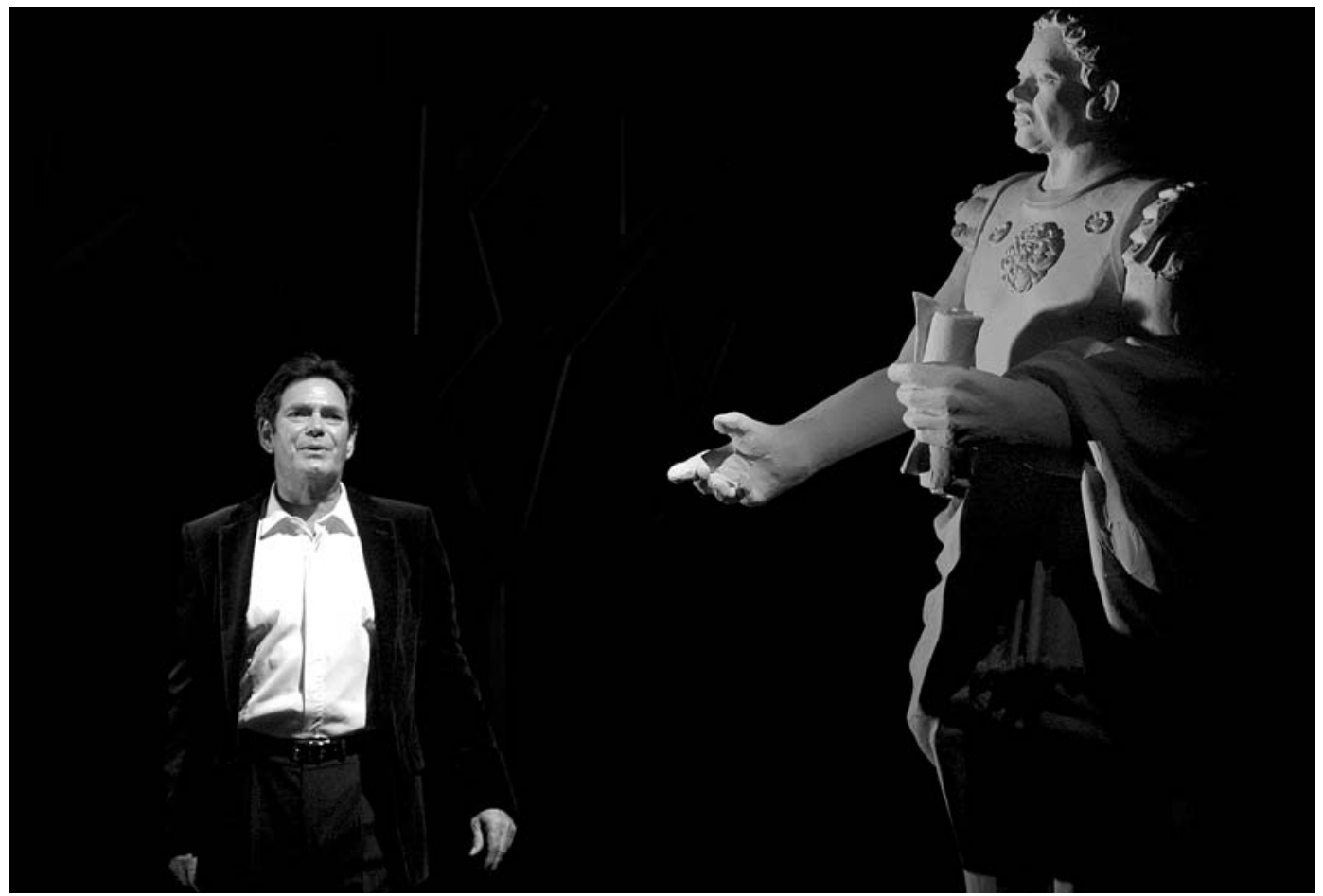

do nosso património teatral clássico e universal, e numa personagem que, como escreve o tradutor Coimbra Martins no texto que prefacia a edição ${ }^{2}$ da versão agora posta em cena acerca de D. Juan, já "deu a volta ao mundo".

$\mathrm{Na}$ verdade, incluir Molière, hoje, numa política de repertório significa, como esta leitura de D. Juan pela companhia de Almada não deixa de o mostrar, antes de mais nada, enfrentar o desafio de, voltando aos chamados "grandes" textos dos igualmente "grandes" autores, não só com eles elaborar um objecto artístico original mas, também, ao visitá-los de novo, com eles continuar a construir uma leitura do mundo que sirva para o seu espectador e para a compreensão do mundo em que vivemos.

Nesse sentido, para esta encenação, Joaquim Benite adopta um tratamento actual do mítico D. Juan de Molière. A exclusão do peso eventual de uma historicização do texto é perceptivel de imediato na tradução utilizada, que, de acordo com o tradutor Coimbra Martins, optou por fugir ao literalismo de modo a favorecer a "maravilhosa oralidade e espontaneidade das peças de Molière" ${ }^{3}$. Optando pelo rigor e pela sobriedade, o conjunto do espectáculo é pautado pela coerência entre a proposta de leitura dramatúrgica, as escolhas de encenação e cenografia, e o jogo dos intérpretes. A actualidade de uma obra tão carregada de história como o é D. Juan também é evidenciada no guarda-roupa predominantemente escuro, tanto nos fatos dos homens como na indumentária de D. Elvira, em contraste com peças de vestuário com conotações contemporâneas, de cor branca, para as jovens camponesas Carlota e Maturina, ou ainda com a referência mais rústica, e mais tradicional em termos teatrais, da roupa do camponês Joaquim. Os elementos de cenografia concebidos por Manuel Graça Dias e Egas José Vieira seguem igual propósito. Sob uma iluminação geralmente fria, o palco, imenso, sombrio, que o encenador utiliza na sua totalidade ao longo de toda a peça, permanece vazio, sendo apenas ocupado por mesas de metal e cadeiras austeras, nas cenas de interior. Nas cenas de exterior, a referência à natureza é distanciada pela introdução da reprodução de um quadro paisagista moderno que, agressivo, apaga qualquer tentação de bucolismo

romanesco. Um pano de veludo vermelho que cobre parte da mesa da ceia para o penúltimo acto deixa ao espectador a mesma impressão de violência latente.

Numa tal opção, de despojamento quase minimalista, o palco reencontra a sua função primordial enquanto espaço destinado a acolher e destacar o jogo dos actores, em particular o par Esganarelo / D. Juan no qual assentam as opções dramatúrgicas orientadoras do espectáculo, baseadas numa revisão do conflito recorrente no teatro clássico entre amo e criado.

De facto, esta proposta dramatúrgica é focalizada no modo como um poder discricionário de um privilegiado, socialmente superior, se exerce sobre um outro individuo, dependente dele em tudo, desde logo na sobrevivência material, como o mostra de forma violenta a cena da ceia em que Esganarelo é intimado a "devolver" a comida que "desviou" da mesa do amo. Quanto à dependência moral e intelectual, apesar de ter prazer em expressar o seu sentir sobre todas as questões que marcam o percurso polémico do amo, é visivel a sua desigualdade quando a sua explicação "filosófica" sobre o "dois e dois são quatro", única crença de D. Juan, seu amo, apenas resulta numa penosa e delirante exibição verbal.

Entre D. Juan e Esganarelo não há cumplicidade. E compete à fábula desvendar, ao mesmo tempo que questionar, os limites para a afirmação de uma liberdade individual absoluta, fundada no prazer e no pensamento libertino e agnóstico, quando é reposta na complexidade da rede das relações inter-subjectivas e inter-humanas, principalmente quando os seres são entendidos como membros de uma sociedade desigual. Fiel ao projecto de Molière, o espectáculo constrói um retrato de D. Juan reenviado para a pressão da realidade dos valores que juntamente com árvores de um recorte estilizado e quase 


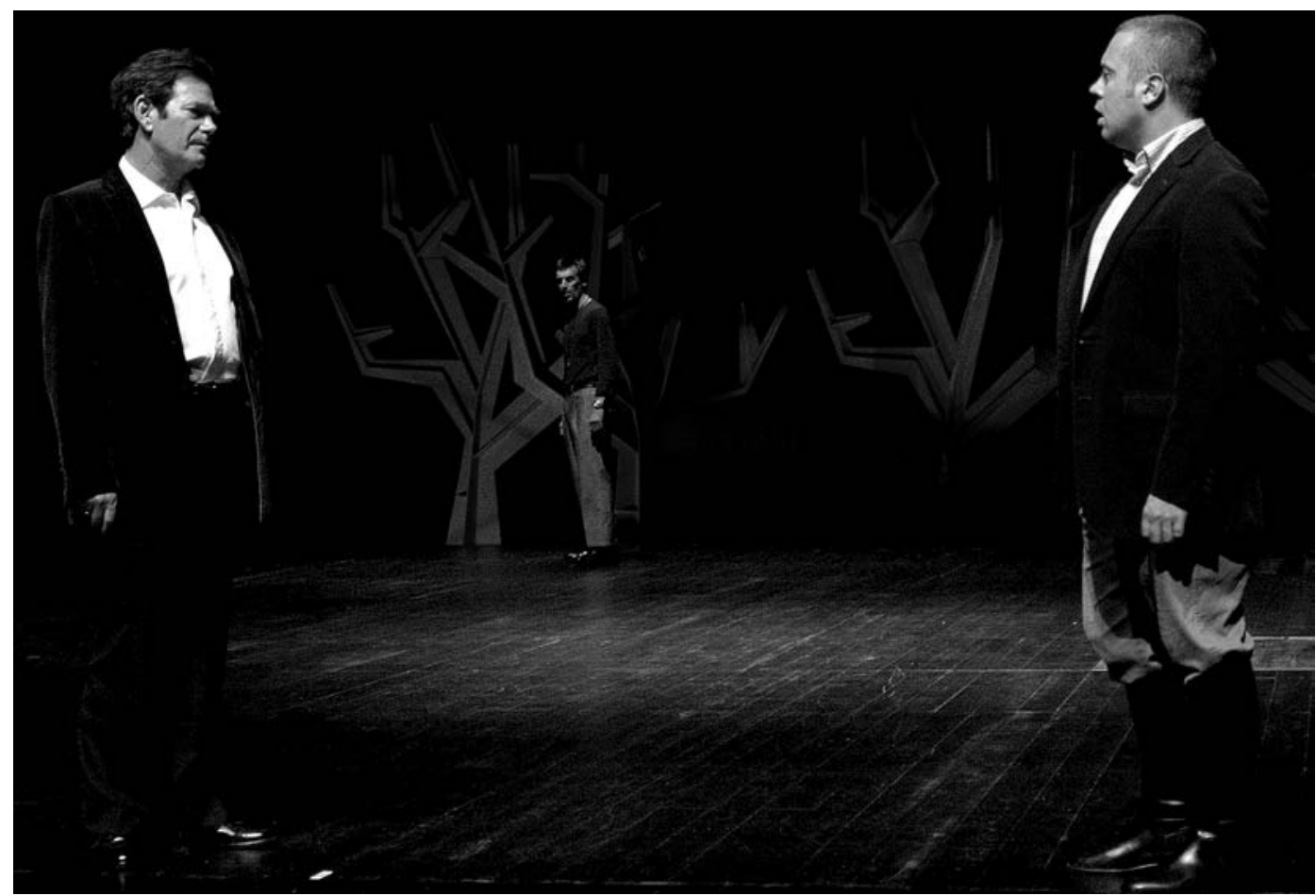

sustentam a sociedade em que vive, aliás pouco diferente da nossa, das suas normas, e que, após o brio inicial de um discurso apenas orientado pela afirmação do prazer da conquista, é lamentavelmente absorvido pelo Inferno que o atira para o subpalco. Respeitando a unidade de tempo, Molière condensa num só dia todas as razões para o merecimento de uma punição fatal, e confronta o espectador com uma sequência de acções marcadas pela crueldade e pela frieza de D. Juan, em particular para com D. Elvira e para com o pai, pela prepotência e pelo desprezo arrogante do aristocrata ("le grand seigneur méchant homme") para com os inferiores, bem patentes nas cenas das camponesas seduzidas e do camponês sovado, ou na da visita do credor, o alfaiate gozado e expulso com brutalidade. Mas é a tirania exercida sobre Esganarelo, aquele que depende de um amo que julga criticamente e que despreza, mas que se diz dominado pelo medo, que acaba por sobressair nesta leitura de $D$. Juan. A veemência da denúncia inicial do seu desacordo com o amo feita na ausência de D. Juan por um Esganarelo que, neste início de peça, tem tudo do fanfarrão, transformar-se-á numa última revolta diante da perda irreversivel dos seus ordenados em atraso. A encenação revela-o como encerrado na sua função de criado, pelo traje próprio para o trabalho e pela redundância da sua função enquanto maquinista de cena encarregado de dirigir, com um apito, as intervenções dos seus "colegas". Desprovido de qualquer heroísmo, posiciona-se no fundo da cena ou tem atitudes de claro alheamento - algo cobarde na cena com os camponeses - ou de ironia disfarçada em comentários indirectos, de resto facilmente silenciados por qualquer reparo mais brutal do seu amo, nas inúmeras cenas que apenas o apresentam como espectador involuntário, se bem que distante, das acções do seu amo.

Menos marcada pela sensualidade e pelo erotismo do corpo (permanentemente enamorado) de D. Juan - duas vertentes que seriam igualmente pertinentes em tal personagem -, a construção do jogo do intérprete de D.
Juan parte sobretudo da força da palavra neste texto magnífico que Molière nos deixou, reforçando a sua clareza numa relação directa com o público, preferencialmente situada no proscénio. 0 texto resulta assim como discurso sedutor e perigoso: sedutor pela sua capacidade transgressiva e pela sua ousadia, e também pela sua surpreendente actualidade temática, sobretudo na sátira dos inimigos de estimação do dramaturgo - médicos, hipócritas, gente dita honrada e censores de toda a espécie ${ }^{4}-$, mas perigoso também pela sua repetida surdez na relação com outrem, em particular com quem o ama ou quem o ameaça. Resulta deste modo um D. Juan tragicamente condenado por ele próprio a ser excluído e castigado. Mantido nessa contradição, o espectáculo não procura responder de maneira taxativa a um qualquer pedido de tomada de posição quanto à aceitabilidade quer dos valores que movem a personagem central, quer das recriminações das suas vitimas. 0 texto de Molière continha, e ainda contém, uma clara ironia quanto à sociedade "bem pensante", fundada na repressão do desejo e do prazer, e até do racionalismo que apenas poderá encontrar no século seguinte uma aceitação não só teórica como prática, com 1789 e o fim do dogmatismo cego e dos privilégios de classe injustamente fundados.

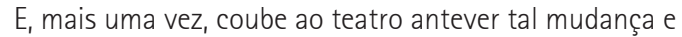
expressá-la na ficção, no poder das palavras.

Com efeito, quer na sua concepção mais fortemente enraizada na tradição europeia e universal, quer na sua inevitável dimensão mítica, Molière significa e resume uma concepção do teatro assente no papel e no valor incontestáveis de um texto de partida. E na sua leitura, Joaquim Benite revela com clareza de que maneira uma prática teatral séria, atenta à complexidade da problemática dos "clássicos", pode dar resposta à questão do seu sentido actual, indo além do seu estatuto de monumento consagrado pelo tempo, e como, apesar dos séculos que deles nos separam, podemos com eles celebrar os poderes do teatro que, nesta comédia de Molière, tão brilhantemente resistiram à passagem do tempo.
${ }^{4}$ É contra a proibição do tabaco pelos Jesuitas que Molière abre a peça com o elogio do tabaco por Esganarelo envolvido numa nuvem de fumo, cena que hoje em dia ganha uma dimensão dificil de imaginar na época de Molière. 